\title{
Histone modification enhances the effectiveness of IL-13 receptor targeted immunotoxin in murine models of human pancreatic cancer
}

\author{
Toshio Fujisawa, Bharat H Joshi and Raj K Puri
}

\begin{abstract}
Background: Interleukin-13 Receptor $\alpha 2$ (IL-13R $\alpha 2$ ) is a tumor-associated antigen and target for cancer therapy. Since IL-13R $\alpha 2$ is heterogeneously overexpressed in a variety of human cancers, it would be highly desirable to uniformly upregulate IL-13R 2 expression in tumors for optimal targeting.

Methods: We examined epigenetic regulation of IL-13RoL in a murine model of human pancreatic cancer by Bisulfite$P C R$, sequencing for DNA methylation and chromatin immunoprecipitation for histone modification. Reverse transcription-PCR was performed for examining changes in IL-13R 2 mRNA expression after treatment with histone deacetylase (HDAC) and c-jun inhibitors. In vitro cytotoxicity assays and in vivo testing in animal tumor models were performed to determine whether HDAC inhibitors could enhance anti-tumor effects of IL-13-PE in pancreatic cancer. Mice harboring subcutaneous tumors were treated with HDAC inhibitors systemically and IL-13-PE intratumorally.
\end{abstract}

Results: We found that CpG sites in IL-13R $\alpha 2$ promoter region were not methylated in all pancreatic cancer cell lines studied including IL-13Ra2-positive and IL-13Ra2-negative cell lines and normal cells. On the other hand, histones at IL-13R $\alpha 2$ promoter region were highly-acetylated in IL-13R $\alpha 2$-positive but much less in receptornegative pancreatic cancer cell lines. When cells were treated with HDAC inhibitors, not only histone acetylation but also IL-13Ra2 expression was dramatically enhanced in receptor-negative pancreatic cancer cells. In contrast, HDAC inhibition did not increase IL-13Ro2 in normal cell lines. In addition, c-jun in IL-13Ro2-positive cells was expressed at higher level than in negative cells. Two types of c-jun inhibitors prevented increase of IL-13R 22 by HDAC inhibitors. HDAC inhibitors dramatically sensitized cancer cells to immunotoxin in the cytotoxicity assay in vitro and increased IL-13Ro2 in the tumors subcutaneously implanted in the immunodeficient animals but not in normal mice tissues. Combination therapy with HDAC inhibitors and immunotoxin synergistically inhibited growth of not only IL-13R $\alpha 2$-positive but also IL-13Ra2-negative tumors.

Conclusions: We have identified a novel function of histone modification in the regulation of IL-13Ra2 in pancreatic cancer cell lines in vitro and in vivo. HDAC inhibition provides a novel opportunity in designing combinatorial therapeutic approaches not only in combination with IL-13-PE but with other immunotoxins for therapy of pancreatic cancer and other cancers.

\section{Introduction}

Interleukin-13 Receptor $\alpha 2$ (IL-13R $\alpha 2)$ is a high affinity receptor for the Th2 derived cytokine IL-13 and a known cancer testis antigen [1,2]. IL-13R $\alpha 2$ is over expressed in a variety of human cancers including malignant glioma, head and neck cancer, Kaposi's

\footnotetext{
* Correspondence: raj.puri@fda.hhs.gov
Tumor Vaccines and Biotechnology Branch, Division of Cellular and Gene

* Correspondence: raj.puri@fda.hhs.gov
Tumor Vaccines and Biotechnology Branch, Division of Cellular and Gene Therapies, Center for Biologics Evaluation and Research, Food and Drug Administration, Bethesda, MD, USA
}

(c) 2011 Fujisawa et al; licensee BioMed Central Ltd. This is an Open Access article distributed under the terms of the Creative Commons Attribution License (http://creativecommons.org/licenses/by/2.0), which permits unrestricted use, distribution, and reproduction in any medium, provided the original work is properly cited. sarcoma, renal cell carcinoma, and ovarian carcinoma can be effectively targeted by a recombinant immunotoxin, consisting of IL-13 and truncated pseudomonas exotoxin (IL-13-PE) [8-11]. IL-13-PE is highly cytotoxic to tumor cells in vitro and in vivo that express high levels of IL-13R $\alpha 2$ [12]. Several phase I and II clinical trials, and one phase III clinical trial, evaluating the safety, tolerability, and efficacy of this agent have been completed in patients with recurrent glioblastoma 
multiforme $[13,14]$. Most recently, we have demonstrated expression of IL-13R $\alpha 2$ in human pancreatic ductal adenocarcinoma [15]. Seventy-one percent of pancreatic tumors overexpressed IL-13R $\alpha 2$ chain. Pancreatic tumors were also successfully targeted by IL-13PE in an animal model of human cancer $[15,16]$. Thus, IL-13R $\alpha 2$ is currently being assessed as a cancer therapy in a variety of preclinical and clinical trials $[4,17,18]$

The significance of IL-13R $\alpha 2$ expression in cancer is not known and the mechanism of its upregulation is still not clear. Epigenetic mechanisms such as DNA methylation and histone modification are known to be involved in many disease pathogenesis including cancer [19]. DNA methylation occurs on cytosines that are followed by guanines (CpG dinucleotides) and is usually associated with gene silencing [20]. Histones are modified at several different amino acid residues and with many different modifications including methylation, acetylation, phosphorylation and ubiquitination. Some lysine residues can either be methylated or acetylated, and there are three different possibilities for each methylated site [21]. Histone modification can be transiently altered by the cell environment [22]. Mainly, gene expression is activated by histone acetylation and decreased by methylation. Histone acetylation induced by histone acetyltransferase (HAT) is associated with gene transcription, while histone hypoacetylation induced by histone deacetylase (HDAC) is associated with gene silencing [23].

HDAC inhibition results in increased acetylation in histones and causes over expression of some genes. HDAC inhibitors are grouped into various classes based on their structures [24]. Trichostatin A (TSA), suberoylanilide hydroxamic acid (SAHA), and sodium butyrate $(\mathrm{NaB})$ are commonly studied HDAC inhibitors. These inhibitors induce cell growth arrest and apoptosis in a broad spectrum of transformed cells [25]. Because of these characteristics, HDAC inhibitors are being tested in the clinic for cancer therapy. Two HDAC inhibitors, SAHA and Romidepsin, are licensed by FDA for the treatment of cutaneous T-cell lymphoma [26].

In the present study, we have examined the epigenetic regulation of the $I L-13 R \alpha 2$ gene in pancreatic cancer cell lines and investigated whether the $I L-13 R \alpha 2$ gene can be modulated by epigenetic mechanisms. We have also examined the effect of HDAC inhibitors on IL$13 R \alpha 2$ expression. We demonstrate for the first time that three different HDAC inhibitors dramatically upregulate IL-13R $\alpha 2$ in pancreatic cancer cell lines expressing no or low levels of IL-13R $\alpha 2$. These inhibitors also modestly upregulated IL-13R $\alpha 2$ in cells expressing higher levels of IL-13R $\alpha 2$. More importantly, HDAC inhibitors sensitized pancreatic tumor cells to IL-13-PE and mediated enhanced sensitivity even though these cells did not naturally express IL-13R $\alpha 2$. A combination therapy of HDAC inhibitors and IL-13-PE demonstrated a pronounced anti-tumor effect in human tumor bearing immunodeficient mice indicating a synergistic impact on tumor response. Thus, a novel combination of HDAC inhibitors and IL-13-PE may have a prominent role in pancreatic cancer or other cancer therapies in the clinic.

\section{Materials and methods}

\section{Cell culture and reagents}

Pancreatic cancer cell lines and human umbilical vein endothelial cell line (HUVEC) were obtained from the American Type Culture Collection (Manassas, VA). Human normal gingival fibroblasts (HGF) was obtained from Sciencell (San Diego, CA) and human pancreatic ductal epithelial cells (HPE) from Cell Systems (Kirkland, WA). Renal cell carcinoma (PM-RCC) cell line was developed in our laboratory [4]. Recombinant IL-13-PE was produced and purified in our laboratory $[9,11,27]$. Trichostatin A (TSA), sodium butyrate $(\mathrm{NaB})$ and SP600125 were purchased from Sigma-Aldrich (St. Louis, MO). SR11302 was purchased from Tocris Bioscience (Ellisville, MO). Suberoylanilide Hydroxamic Acid (SAHA) was purchased from Selleck (Houston, TX).

\section{Reverse transcription-PCR}

Quantitative reverse transcription-PCR (qRT-PCR) and RT-PCR were performed as described previously $[28,29]$ using a SYBR 1 reagent kit (Bio-Rad, Hercules, CA). Mouse IL-13R $\alpha 2$ and $\beta$-actin primers were purchased from QIAGEN (Valencia, CA). Gene expression was normalized to $\beta$-actin before the fold change in gene expression was determined.

\section{Chromatin immunoprecipitation (ChIP) assays}

ChIP assays were performed using a ChIP assay kit (Millipore, Billerica, MA). To cross-link DNA with chromatin, $1 \times 10^{6}$ cells were incubated for $5 \mathrm{~min}$ in $1 \%$ formaldehyde at $37^{\circ} \mathrm{C}$. The cells were harvested, washed with phosphate buffered saline (PBS), resuspended in lysis buffer and 200-1000 bp fragments of DNA from chromatin were prepared as recommended by the manufacturer. One hundredth of the resultant solution was used as an internal control. The remainder was immunoprecipitated for 16 hours at $4^{\circ} \mathrm{C}$ using anti-acetylated histone $\mathrm{H} 3$ and anti-acetylated histone $\mathrm{H} 4$ antibodies (Millipore, Billerica, MA). The precipitated immune complexes were recovered using protein A-agarose, and then purified using QIAamp DNA mini kit (QIAGEN). Samples were analyzed by qPCR to determine a ratio of histone acetylation at the $I L-13 R \alpha 2$ promoter site using propriety primers Hs04516601_cn for IL-13R $\alpha 2$ gene and RNase P/TERT reference copy number primers 
after following the manufacturer's instructions (Applied Biosystems, Foster City, CA).

\section{Bisulfite-PCR and sequencing}

Bisulfite sequencing was performed using CpGenome Fast DNA Modification Kit (Millipore, Billerica, MA). Briefly, $1 \mu \mathrm{g}$ of genome DNA was incubated for 16 hours at $50^{\circ} \mathrm{C}$ with sodium bisulfite solution. The modified DNA was purified by DNA binding column. The promoter region of $I L-13 R \alpha 2$ gene was amplified by PCR using specific primer pairs, FW: 5'-TTGGGGAGAAAGAGAGATTTG-3', and BW: 5'-CAAACTTACCCCACCCAAAA-3'. The PCR products were cloned into pCR2.1 vector using a TOPO-cloning KIT (Invitrogen, Carlsbad, CA) and sequenced using an ABI377 automated sequencer. At least 10 clones were sequenced for each cell line.

\section{AP-1 activation assay}

Nuclear extracts from cell lines were collected using the Transfactor Extract Kit (Active Motif, Carlsbad, CA) and tested for DNA binding activity using the AP-1 family TransAM Kit (Active Motif) according to the manufacturer's instructions [28].

\section{Immunohistochemistry (IHC) and Immunocytochemistry (ICC)}

Expression of human and mouse IL-13R $\alpha 2$ protein in pancreatic cancer cell lines and mouse organs was observed by indirect immunofluorescence-immunostaining as described previously $[28,30]$ using anti-mouse monoclonal and anti-human IL-13R $\alpha 2$ polyclonal antibodies ( $\& \& D$, Minneapolis, MN). Tissue samples were fixed in $10 \%$ formalin solution for IHC and human cells were fixed by $4 \%$ paraformaldehyde (PFA) for ICC. The nucleus was counterstained by DAPI.

\section{IL-13R $\alpha 2$ gene knockdown by RNA interference}

Retrovirus-mediated RNA interference was performed using the pSuper RNAi system (Oligoengine, Seattle, WA) following the manufacturer's instructions as described previously $[16,28]$.

\section{Protein synthesis inhibition assay}

In vitro cytotoxic activity of IL-13 cytotoxin (IL-13-PE) was measured by the inhibition of protein synthesis as described earlier [11]. All assays were performed in quadruplicate and data are shown as mean \pm SD.

\section{Tumor xenograft studies}

Panc- 1 and ASPC- 1 cells $\left(2 \times 10^{6}\right)$ were injected s.c. in the left flank of female athymic nude mice. From day 4 after tumor implantation, $5 \mathrm{mg} / \mathrm{kg}$ TSA was subcutaneously (s.c.) injected every alternative days or $25 \mathrm{mg} / \mathrm{kg}$
SAHA were intraperitoneally (i.p.) injected daily for 14 days. From day 5, 50 or $100 \mu \mathrm{g} / \mathrm{kg}$ IL-13-PE or PBS/ $0.2 \%$ human serum albumin (vehicle) were intratumorally (i.t.) injected daily for 14 days. Mice body weight and tumor size was measured every 4-7 days from day 4. Measurement was continued until more than one tumor reached $20 \mathrm{~mm}$ in diameter in each group. Their appearances were observed through out the entire experiment for detecting toxic side effects from the treatment. Animal studies were conducted under an approved protocol in accordance with the principles and procedures outlined in the NIH Guide for the Care and Use of Laboratory Animals.

\section{Statistical analysis}

The data were analyzed for statistical significance using Student's $t$ test for comparison between two groups and ANOVA among more than two groups. All experiments including the animal model were repeated at least twice.

\section{Results}

\section{IL-13R $\alpha 2$ expression in pancreatic cancer cell lines}

Eleven pancreatic cancer cell lines and three types of normal cell lines (fibroblast, umbilical vein endothelial cells and pancreatic ductal epithelial cells) were examined for IL-13R $\alpha 2$ expression. qRT-PCR analysis identified five pancreatic cancer cell lines (HS766T, MIAPaCa2, KLM, SW1990 and BxPC3), which expressed high levels of $I L-13 R \alpha 2 \mathrm{mRNA}$, and six cell lines (Panc-1, ASPC-1, HPAF-II, Mpanc96, PK-1 and Capan-1) expressed low levels $I L-13 R \alpha 2$ mRNA (negative cell line) (Figure 1A). All three normal cell lines showed extremely low levels of $I L-13 R \alpha 2$ mRNA. We also examined IL-13R $\alpha 2$ protein expression in these cell lines by flow-cytometric analysis using monoclonal antibody to IL-13R $\alpha 2$. These results essentially corroborated the mRNA results (data not shown) $[15,31]$.

\section{Mutation analysis of IL-13R $\alpha 2$ cDNA}

We investigated whether there were gene sequence changes in the $I L-13 R \alpha 2$ gene by performing sequencing of $I L-13 R \alpha 2$ cDNA. However, no mutations were detected in any pancreatic cancer cell lines studied (data not shown).

\section{DNA methylation in IL-13R $\alpha 2$ promoter}

We next examined any epigenetic changes in $I L-13 R \alpha 2$ gene. Since there is only one CpG site in the $I L-13 R \alpha 2$ promoter region, we examined DNA methylation at this site [32]. We picked more than 10 independent clones for analysis. In at least $80 \%$ of the clones tested from all cell lines including three normal cell lines, no methylation was detected (Figure 1B). As a control, we also 


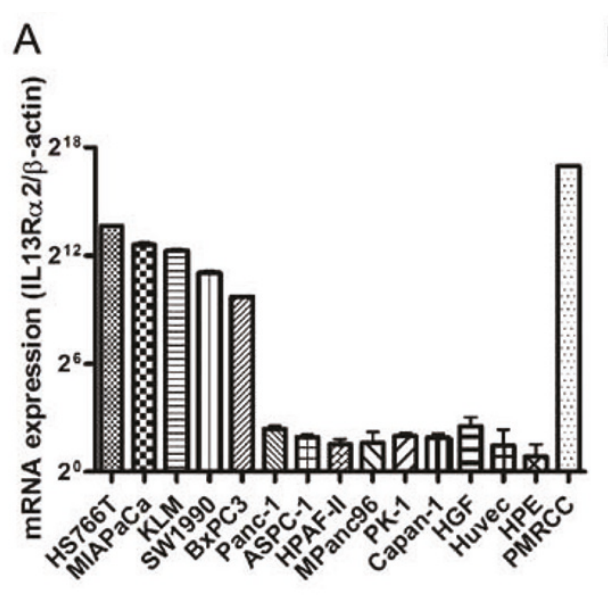

C
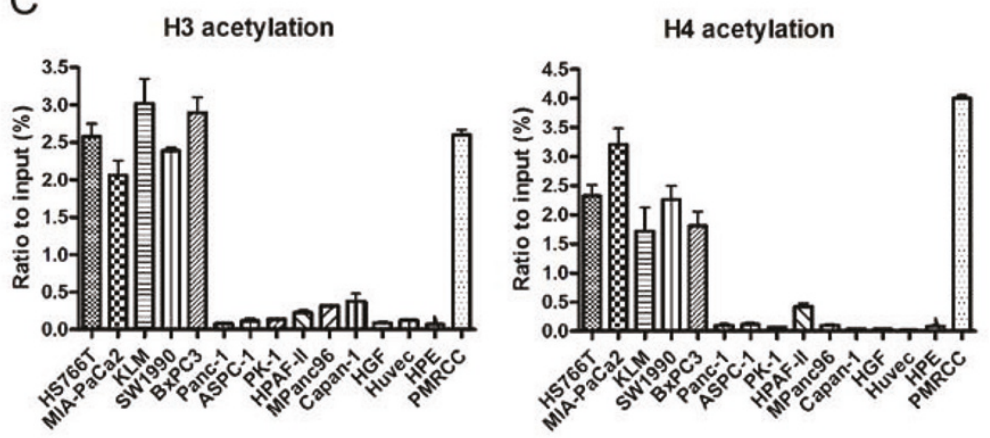

D

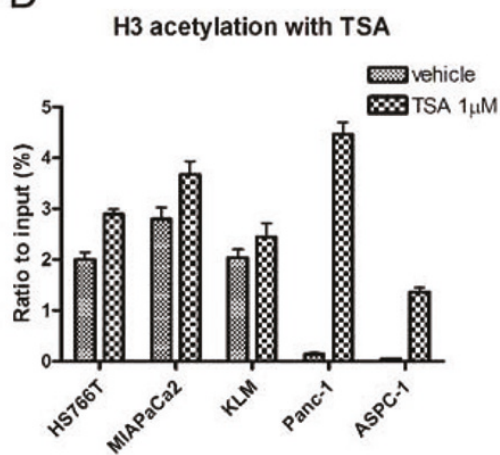

B

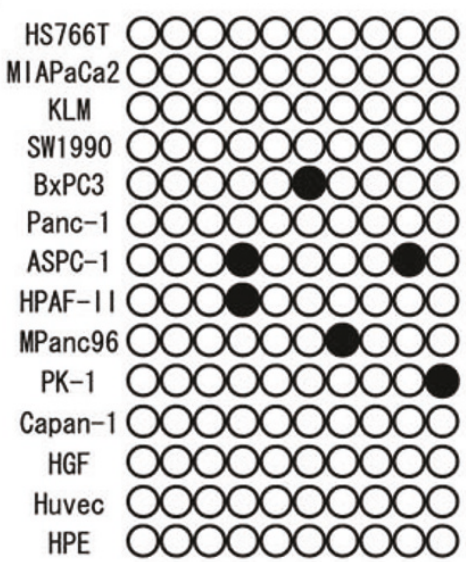

H4 acetylation



H3K9 Methylation with TSA
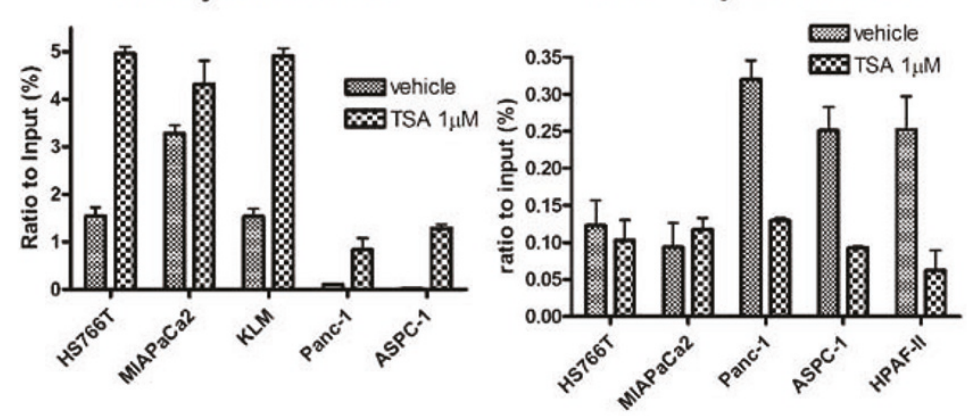

Figure 1 IL-13R $\alpha 2$ expression in pancreatic cancer and normal cell lines and DNA methylation and Histone modification of IL-13R $\alpha 2$ promoter. A, qRT-PCR for IL-13Ro2 expression in pancreatic cancer and normal cell lines was performed. Data shown is ratio of human IL$13 R \alpha 2 / \beta$-actin expression and multiplied by $2^{22}$ for convenience. Bars, SD of triplicate determinations. B, Bisulfite-sequencing of IL-13R 2 promoter. Only one CpG site is present within the IL-13Ro2 promoter region. Methylated and unmethylated alleles are shown as solid and open circles, respectively. C, Acetylation and methylation status of histones $\mathrm{H} 3$ and $\mathrm{H} 4$ in pancreatic cancer and normal cell lines. The region around the IL-13Ro2 promoter was amplified by QPCR after ChIP using anti-acetylated histone $\mathrm{H} 3$ and $\mathrm{H} 4$ antibody and anti-methylated H3K9. Results were standardized by amplification of the IL-13Ro2 promoter using DNA before precipitation (Input). D, Acetylation and methylation status of histones $\mathrm{H3}$ and $\mathrm{H} 4$ after incubation with TSA. Cells were incubated with $1 \mu \mathrm{M}$ TSA or vehicle for 24 hours and fixed by $1 \%$ PFA. Results were standardized using DNA before precipitation.

studied DNA methylation of other CpG sites located $\sim 100$ bases upstream from the $I L-13 R \alpha 2$ promoter region. In contrast to the CPG in the IL-13R 22 promoter region, the distant $\mathrm{CpG}$ site showed methylation in all cell lines (Supplementary Figure 1).
Regulation of histone acetylation and methylation in IL$13 R \alpha 2$ promoter region

We also examined histone acetylation of the $I L-13 R \alpha 2$ promoter region using a chromatin-immunoprecipitation technique (ChIP). In all IL-13R $\alpha 2$-positive 
pancreatic cell lines, histone $\mathrm{H} 3$ was highly acetylated compared to IL-13R $\alpha 2$-negative and normal cell lines (Figure 1C). Similar acetylation results were observed for histone $\mathrm{H} 4$. In sharp contrast, the methylation status at the H3K9 site, which is a site for transcriptional repression, was high in IL-13R $\alpha 2$-negative cell lines compared to IL-13R $\alpha 2$-positive cell lines (Figure 1C).

Next, we examined the effect of histone acetylation inhibition by HDAC inhibitors on IL-13R $\alpha 2$ expression. When pancreatic cancer lines expressing undetectable levels of $I L-13 R \alpha 2$ were treated with TSA, histone H3 and $\mathrm{H} 4$ acetylation was dramatically increased. TSA also increased acetylation in pancreatic cancer cells expressing high levels of IL-13R $\alpha 2$ but this increase was less dramatic (Figure 1D). In contrast, TSA caused a significant decrease in H3K9 methylation in pancreatic cancer cells with undetectable levels of IL-13R $\alpha 2$ expression but no change in high IL-13R $\alpha 2$ expressing cell lines (Figure 1D).

\section{Histone deacetylation inhibition increases IL-13R $\alpha 2$ expression in pancreatic cancer cell lines}

As the relationship between histone acetylation and $I L$ $13 R \alpha 2$ expression levels was observed, we tested whether HDAC inhibitors can modulate $I L-13 R \alpha 2$ expression in pancreatic cancer cell lines. Interestingly, similar to histone acetylation, TSA treatment resulted in increased $I L-13 R \alpha 2$ mRNA expression in pancreatic cancer cell lines that normally have undetectable levels of IL-13R $\alpha 2$ expression, while no changes were seen in cells expressing high levels of $I L-13 R \alpha 2$ mRNA or normal cell lines (Figure 2A). Similar results were obtained with another HDAC inhibitor, sodium butyrate $(\mathrm{NaB})$ (Figure 2B).

\section{Role of AP-1 transcription factor activity in IL-13R $\alpha 2$ regulation in pancreatic cancer cell lines}

To determine the mechanism of the differential effect of HDAC inhibition in cells expressing undetectable levels of IL-13R $\alpha 2$, we examined whether the transcription factor (AP-1) is activated in these cell lines as reported by $\mathrm{Wu}$ et al. [32]. We found that pancreatic cancer cell lines that highly express $I L-13 R \alpha 2$ (HS766T, MIAPaCa2, and KLM), and those which express undetectable levels (Panc-1 and ASPC-1), both show high c-jun activity (Supplementary Figure 2A). In contrast, normal cell lines showed low c-jun activity. We did not observe any significant differences in c-Fos activity, another AP-1 member (Supplementary Figure 2B) between cancer and normal cell lines.

Interestingly, when high IL-13R $\alpha 2$-expressing cells were treated with the c-jun $\mathrm{N}$-terminal kinase inhibitor, SP600125, IL-13R $\alpha 2$ expression decreased (Figure 2C), whereas SP600125 had no effect on cells expressing undetectable levels of $I L-13 R \alpha 2$. Another pan-AP-1 inhibitor, SR11302, also decreased $I L-13 R \alpha 2$ expression in IL-13R $\alpha 2$ expressing cell lines in a concentration-dependent manner (Figure 2D). The effects of TSA and SP600125 on IL-13R $\alpha 2$ protein expression in pancreatic cancer cells were also analyzed by IHC. IL-13R $\alpha 2$ protein levels were also found to increase in the presence of TSA and decrease in the presence of SP600125. In addition, SP600125 prevented the increase of IL-13R $\alpha 2$ protein by TSA (Figure 3A).

\section{Stability of upregulated IL-13R $\alpha 2$ expression by HDAC inhibitor}

We examined the stability of upregulated $I L-13 R \alpha 2$ expression in IL-13R $\alpha 2$-expressing and negative pancreatic cancer cell lines when treated with HDAC inhibitor. After treatment with TSA and SP600125 for 24 hours, the drugs were removed and cell culture was continued. $I L-13 R \alpha 2$ expression was still elevated 3 days after TSA removal in $I L-13 R \alpha 2$ undetectable cell lines (Figure 3B). In contrast, in IL-13R $\alpha 2$ positive cell lines, $I L-13 R \alpha 2$ expression returned to pre-treatment levels within 24 hours following SP600125 removal (Figure 3C).

\section{HDAC inhibition increases IL-13 induced matrix metalloproteinases via IL-13R $\alpha 2$ upregulation}

As we have shown that IL-13 can upregulate Matrix metalloproteinases (MMPs) expression in IL-13R $\alpha 2$ expressing pancreatic cancer cell lines [28], we investigated the impact of IL-13R $\alpha 2$ upregulation by HDAC inhibitors by examining IL-13 induced MMPs expression. TSA treatment increased mRNA expression for $M M P s$ through upregulation of $I L-13 R \alpha 2$ after treatment with IL-13 in two IL-13R $\alpha 2$ negative cell lines (Figure 4A). Interestingly, when IL-13 signaling was blocked by an inhibitor of the AP-1 pathway (SP600125), it prevented the increase in MMPs expression by TSA. Thus, MMPs expression showed a positive correlation with $I L-13 R \alpha 2$ expression in IL-13 treated cells.

To confirm whether TSA increased MMPs expression as a result of IL-13R $\alpha 2$ induction, we conducted a knock-down of the $I L-13 R \alpha 2$ gene using two different sequences of siRNA in Panc-1 and ASPC-1 cell lines. $M M P s$ expression was suppressed in $I L-13 R \alpha 2$ knockdown cells treated with TSA (Figure 4B).

\section{HDAC inhibition increases the anti-cancer effect of IL-13- $\mathrm{PE}$ targeting IL-13R $\alpha 2$ in vitro and in vivo}

As HDAC inhibition increased IL-13R $\alpha 2$ expression in IL-13R $\alpha 2$-negative but not in normal cell lines, we examined whether HDAC inhibition enhanced the anticancer effect of IL-13-PE in IL-13R $\alpha 2$-negative 


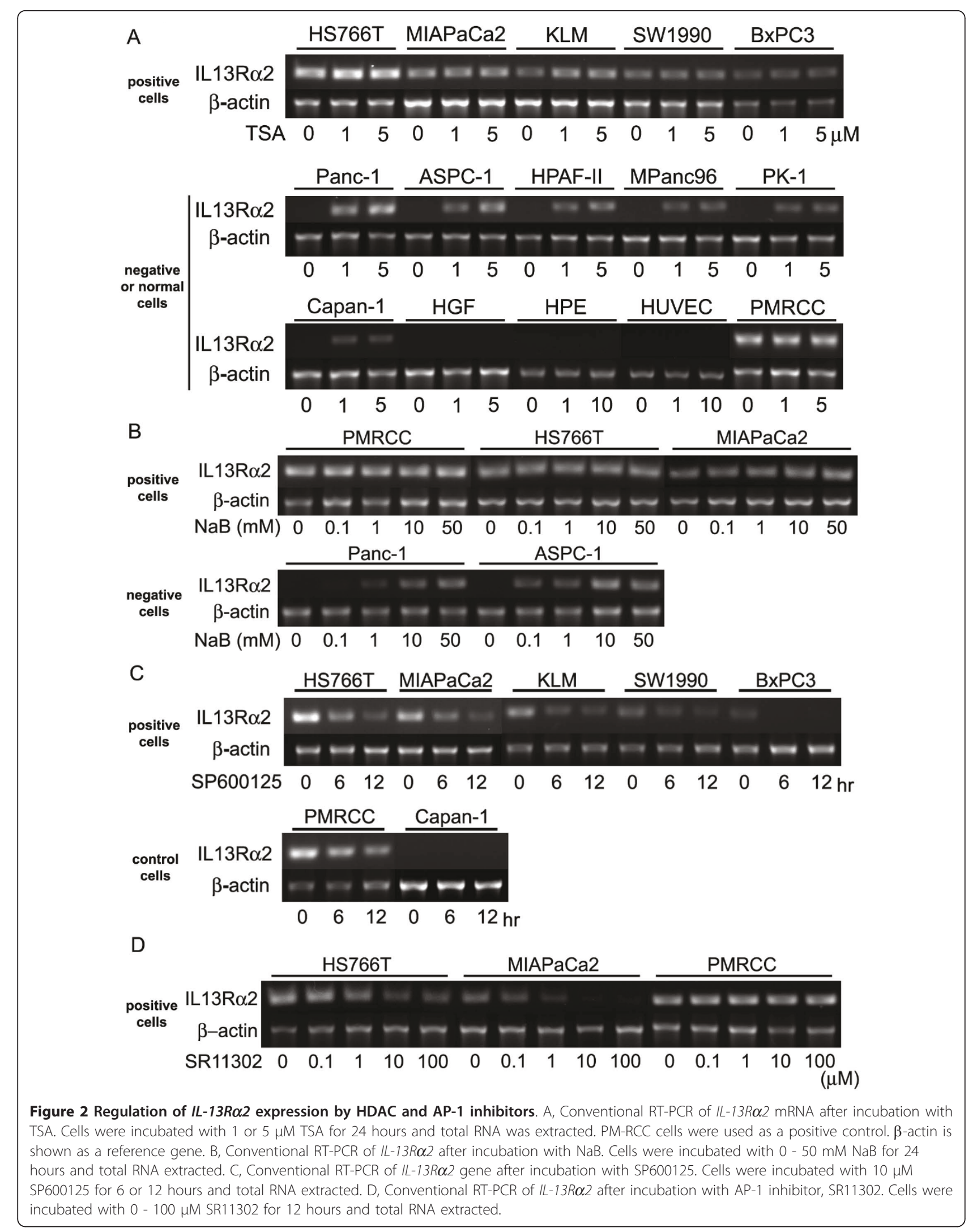




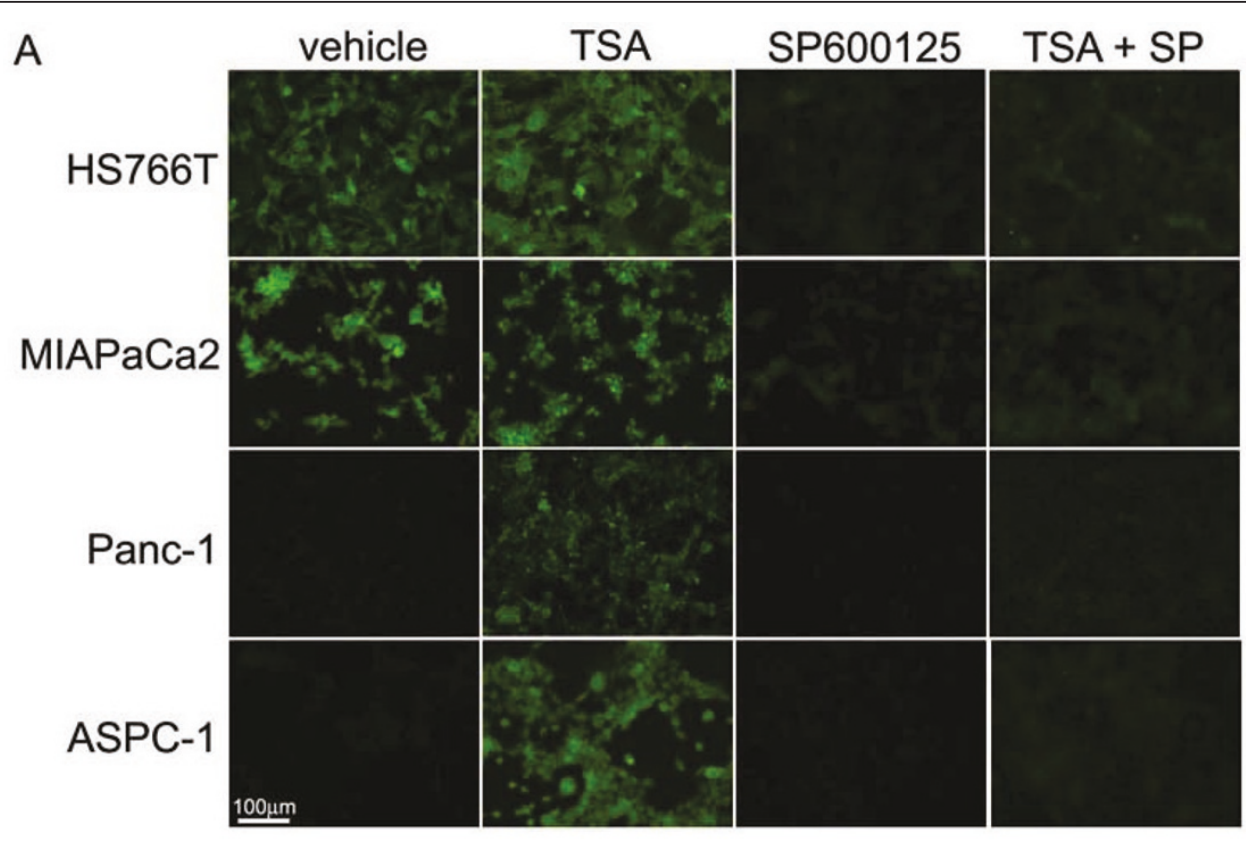

B

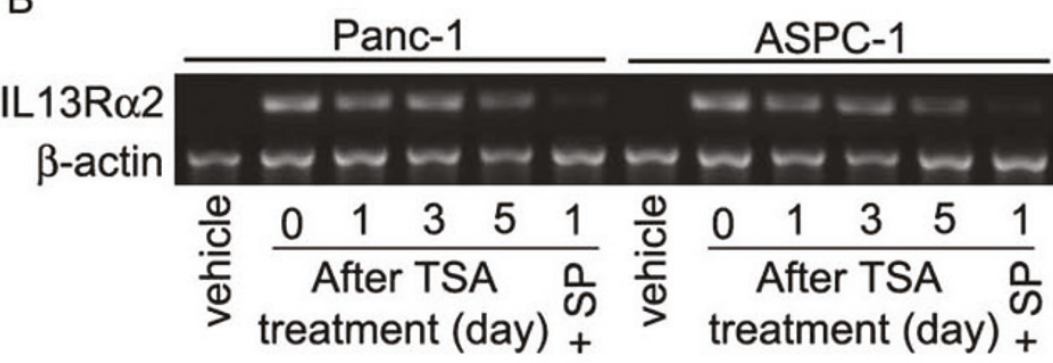

C

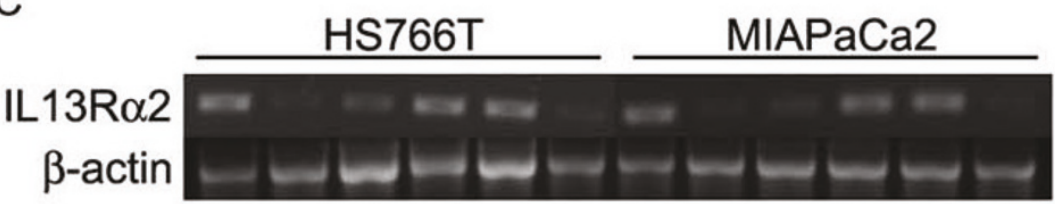

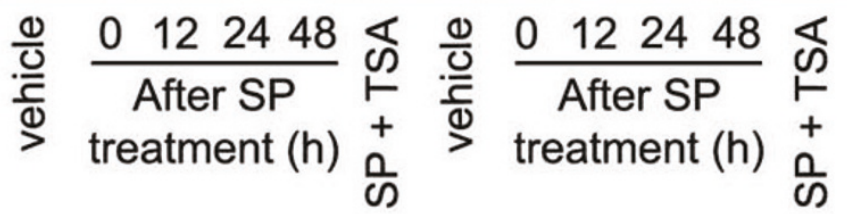

Figure 3 Modulation of IL-13R $\alpha 2$ protein by HDAC and AP-1 inhibitors and stability of IL-13R 2 expression. A, ICC of IL-13R $\alpha 2$ after incubation with TSA and SP600125 is shown. Cells were incubated with $1 \mu \mathrm{M}$ TSA and/or $10 \mu \mathrm{M}$ SP600125 for 24 hours and fixed by 4\% PFA. IL-13R $\alpha 2$ was visualized by Alexa488. Recovery of IL-13R $\alpha 2$ expression after incubation with TSA (B) and SP600125 (C). Cells were incubated with $1 \mu \mathrm{M}$ TSA or SP600125 for 24 hours or 12 hours, respectively and then inhibitors were removed by replacing with new medium without TSA for 1-5 days or SP600125 for 12-48 hours. IL-13Ro2 gene expression was determined by conventional RT-PCR.

pancreatic cancer cell lines. The anti-cancer effect of IL13-PE was evaluated using a protein synthesis inhibition assay in vitro (Figure 5A). IL-13-PE inhibited protein synthesis in IL-13R $\alpha 2$-positive cancer cells $\left(\mathrm{IC}_{50}\right.$ between 10 and $50 \mathrm{ng} / \mathrm{ml}$ ) without TSA, but not in IL13R $\alpha 2$-negative cancer cells nor normal cells $\left(\mathrm{IC}_{50}>\right.$
$1000 \mathrm{ng} / \mathrm{ml}$ ). TSA treatment enhanced the cytotoxicity of IL-13-PE in IL-13R $\alpha 2$-negative cancer cells $\left(\mathrm{IC}_{50} 40-\right.$ $50 \mathrm{ng} / \mathrm{ml}$ with $5 \mu \mathrm{M}$ TSA), but not in normal cells $\left(\mathrm{IC}_{50}\right.$ $>1000 \mathrm{ng} / \mathrm{ml}$ with $5 \mu \mathrm{M}$ TSA).

We next examined the enhancement of the anti-cancer effect of IL-13-PE by HDAC inhibition in xenograft 

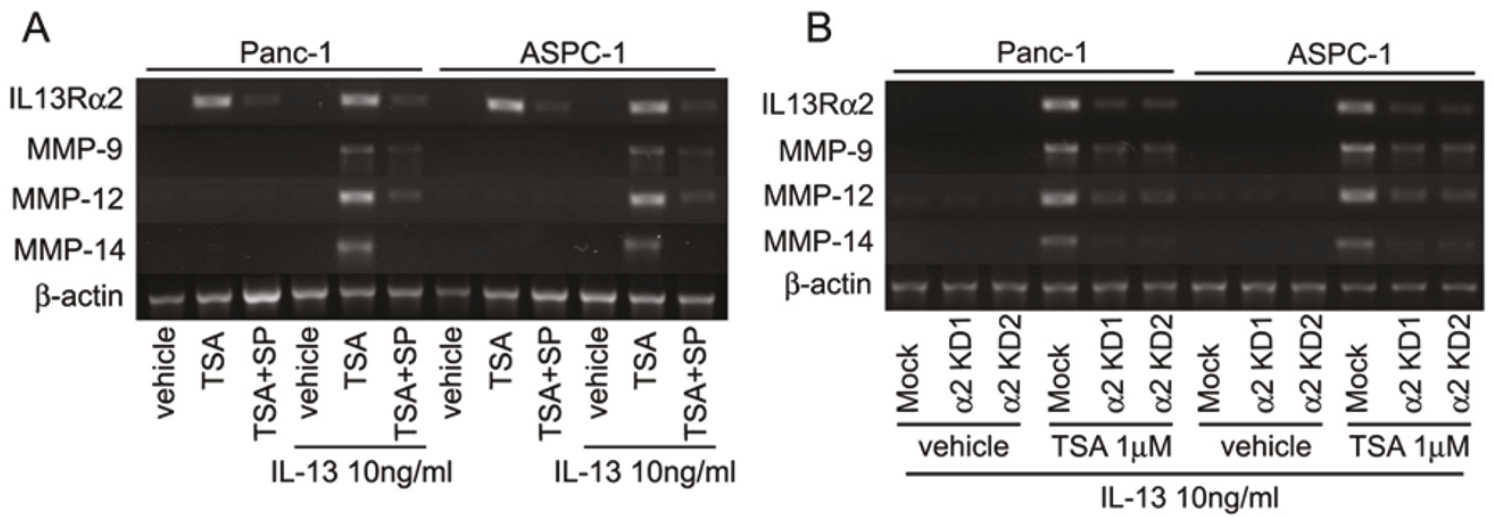

Figure 4 HDAC inhibitor inhibits MMPs expression activated by IL-13 through induction of IL-13R $\alpha 2$. A, Conventional RT-PCR for expression of MMPs was performed after cells were incubated with $1 \mu \mathrm{M}$ TSA and/or $10 \mu \mathrm{M}$ SP600125 for 24 hours. Twenty-two hours prior to harvesting cells, IL-13 was added to the cultured medium and total RNA extracted. $\beta$-actin is shown as a reference gene. B, MMPs expression in IL-13R $\alpha 2$ knock-down $(\alpha 2 \mathrm{KD})$ cells incubated with TSA. Mock and $\alpha 2 \mathrm{KD}$ cells were treated with TSA and IL-13 same as in panel B.

mouse models of human cancer. IL-13R $\alpha 2$-negative pancreatic cancer cell lines (Panc-1 and ASPC-1) were implanted in the flanks of immunodeficient mice and treated with two different HDAC inhibitors, TSA and SAHA followed by IL-13-PE immunotoxin. Neither TSA nor IL-13-PE alone affected the tumor growth, but when combined, a dramatic inhibition of tumor growth was observed (Figure 5B and $5 \mathrm{C}$ ). In contrast, when $I L$ $13 R \alpha 2$ was knocked-down prior to TSA therapy, the anti-tumor effect of combination of TSA and IL-13-PE was completely eliminated compared to mock vector transfected tumors, which showed dramatic tumor response (Figure $5 \mathrm{~B}$ ).

A second HDAC inhibitor, SAHA, itself showed some anti-cancer effect in two tumor models (Figure 5D and $5 \mathrm{E})$. However, when mice were treated with SAHA followed by IL-13-PE, a significant decrease in tumor size was observed. In addition, 50\% of mice showed complete elimination of their tumors in combination group.

Next, we evaluated anti-cancer effect of combination of SAHA and IL-13-PE in IL-13R $\alpha 2$-positive pancreatic cancer model (HS766T and MIA-PaCa2). We observed that IL-13-PE could significantly decrease tumor size in both IL-13R $\alpha 2$-positive tumors (Figure 5F and 5G). But when combined with SAHA, IL-13-PE not only decreased tumor size but also completely eliminated tumors in 66 to $83 \%$ of mice. These data suggest that SAHA can enhance anti-cancer effect of IL-13-PE even in IL-13R $\alpha 2$-positive pancreatic cancers.

We monitored the body weight of mice and their general condition throughout the experimental period and detected no adverse effects caused by the treatment (data not shown). In addition, we observed no organ toxicity in vital organs such as the liver, brain, lung, kidney, pancreas and spleen of IL-13-PE and HDAC inhibitor-treated mice evaluated by histological examination (Supplementary Figure 3)

HDAC inhibitor significantly increased IL-13R $\alpha 2$ in the pancreatic tumors implanted in the mice but not in mice organs

After SAHA and IL-13-PE treatment, implanted tumors and mice organs (liver, brain, pancreas, kidney, spleen and lung) were harvested and IL-13R $\alpha 2$ expression was examined at mRNA and protein levels. Human $I L$ $13 R \alpha 2$ mRNA was significantly increased in tumors in both SAHA treated mice (Figure 6A) and TSA treated mice (Supplementary Figure 4). IL-13-PE treatment had no effect by itself but in combination with SAHA, a significant decrease in $I L-13 R \alpha 2$ expression was observed. In contrast, none of the organs except brain showed a modest increase in mouse $I L-13 R \alpha 2$ mRNA expression (Figure 6B).

We also examined IL-13R $\alpha 2$ protein expression by IHC. Similar to mRNA results, human IL-13R $\alpha 2$ was dramatically increased in tumors from SAHA treated mice and when combined with IL-13-PE, a decrease in IL-13R $\alpha 2$ expression was observed (Figure 6C). In normal tissues, mouse IL-13R $\alpha 2$ was not detected or levels were below the detection limit of the assay in all organs examined (Figure 6D).

\section{Discussion}

We demonstrate for the first time that $I L-13 R \alpha 2$, a tumor antigen, is highly susceptible to epigenetic modulation in pancreatic cancer cell lines. Interestingly, DNA methylation and histone acetylation were differentially regulated in cells overexpressing or not overexpressing IL-13R $\alpha 2$. Histones (H3 and H4) were highly acetylated at the promoter region of $I L-13 R \alpha 2$ in IL-13R $\alpha 2$ - 


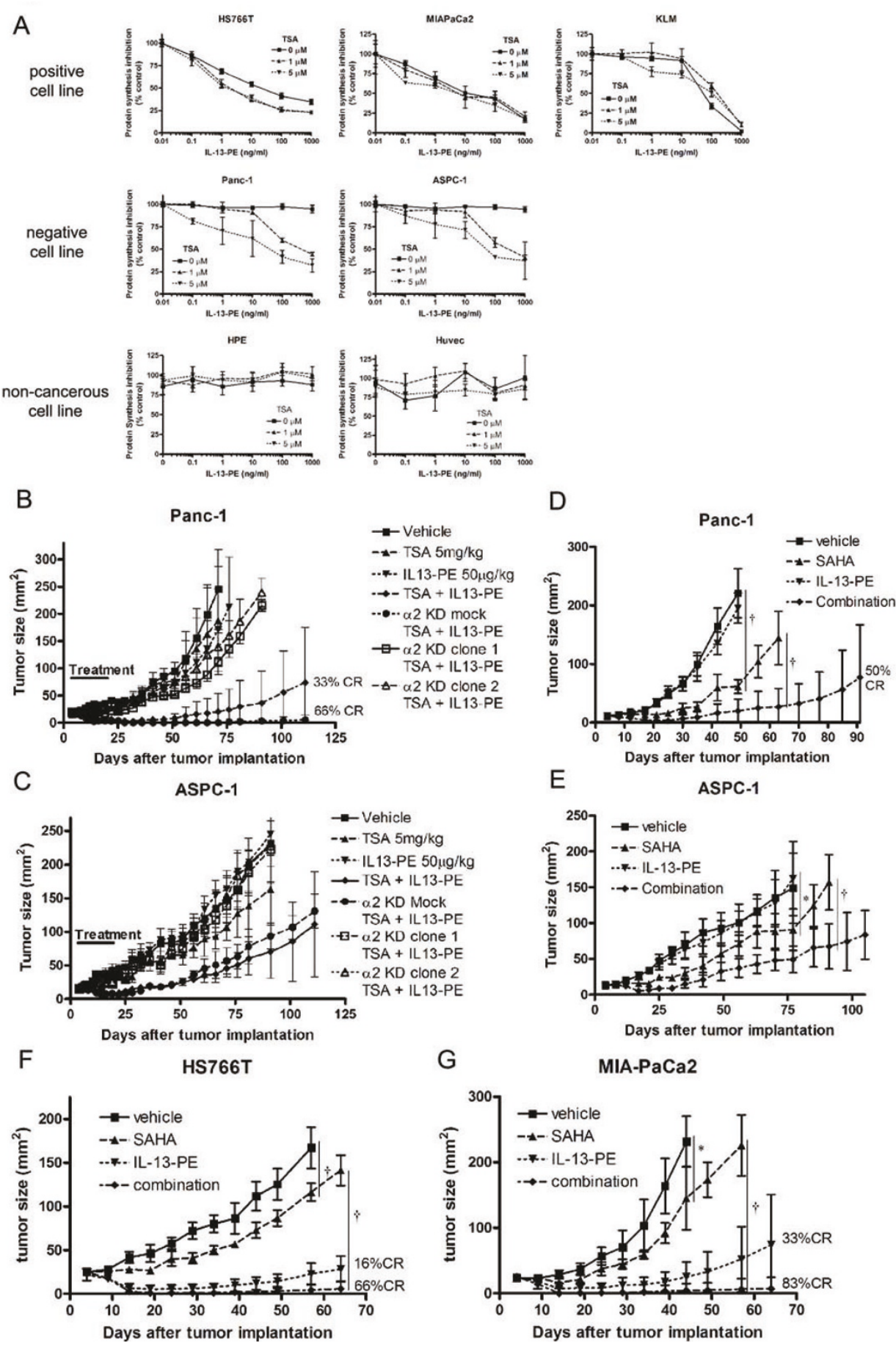

Figure 5 HDAC inhibitors induce anti tumor effect of IL-13R $\alpha 2$ targeted immmunotoxin IL13-PE in IL-13R $\alpha 2$-negative pancreatic cancer cell lines. A, Cytotoxicity assay was performed in IL-13Ro2-negative and -positive pancreatic cancer and normal cell lines. Cells were pretreated with $0-5 \mu \mathrm{M}$ TSA for 24 hours and then treated with $0-1000 \mathrm{ng} / \mathrm{ml} \mathrm{IL-13-PE} \mathrm{for} 20$ hours in leucine-free medium. Protein synthesis was evaluated by $\mathrm{H}^{3}$-leucine incorporation. Percentage cytotoxicity was calculated with no treatment control as $100 \%$. B and C, Regression of IL13Ro2-negative pancreatic tumors (Panc-1 and ASPC-1) treated with $5 \mathrm{mg} / \mathrm{kg}$ TSA and/or $100 \mu \mathrm{g} / \mathrm{kg} \mathrm{IL-13-PE}$ as described in methods. Mock combination means tumors were mock transected with control vector and treated with HDAC inhibitors and IL-13-PE in vivo. D and E, Regression of IL-13Ro2-negative pancreatic tumors treated with SAHA and/or IL-13-PE. Mice were treated daily with i.p. injection of SAHA (25 $\mathrm{mg} / \mathrm{kg})$ from day 4 after tumor implantation for two weeks followed by i.t. injection of IL-13-PE $(100 \mu \mathrm{g} / \mathrm{kg})$ from day 5 for two weeks. F and G, Regression of IL-13Ro2-posotive pancreatic tumors (HS766T and MIA-PaCa2) treated with SAHA and/or IL-13-PE. The schedule of treatment was similar as in panel $D$ and E. Statistical significances are shown by *: $P<0.05,+$ : $P<0.001$. 

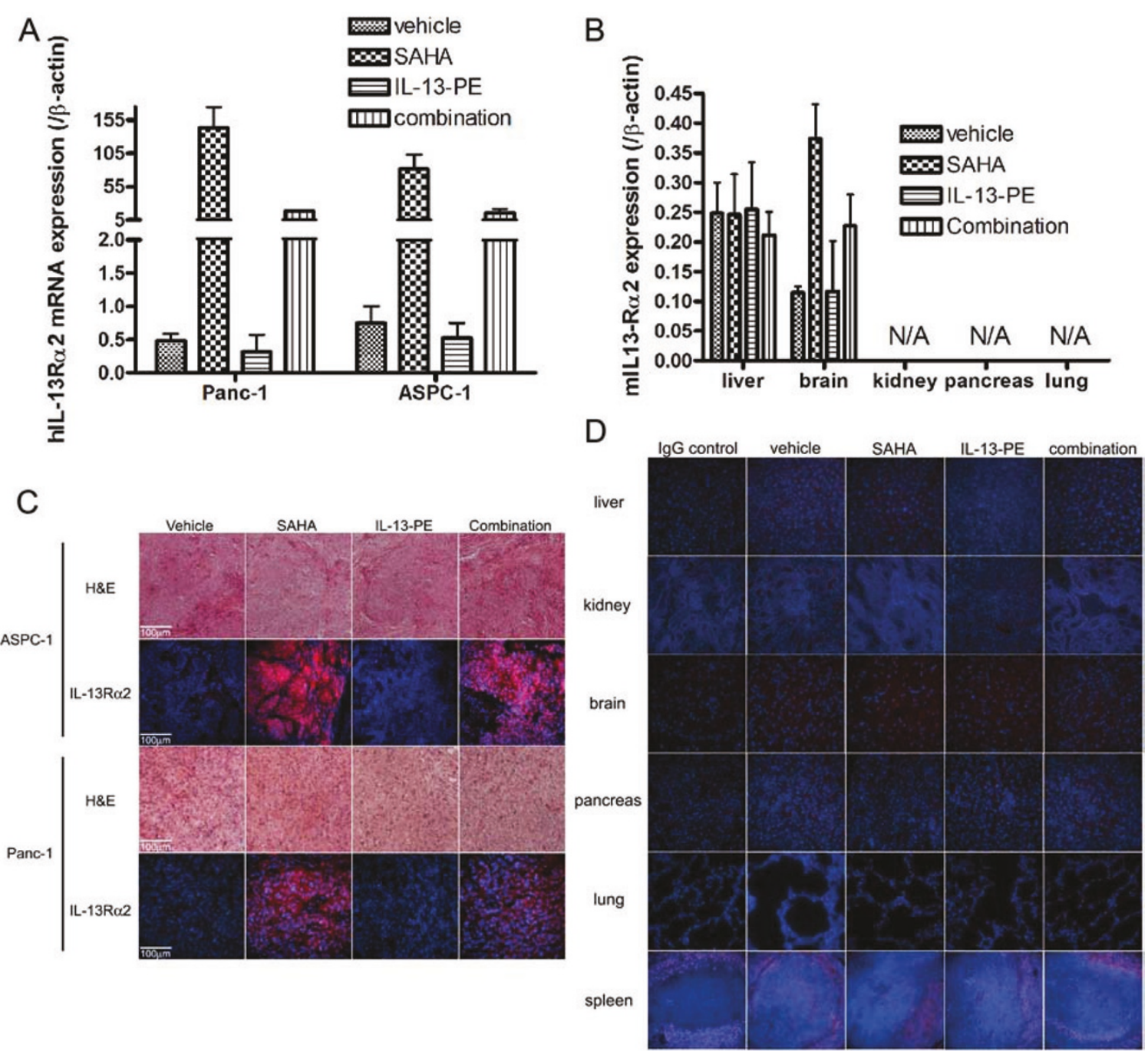

Figure 6 IL-13R $\alpha 2$ expression is upregulated in pancreatic tumors but not in organs of mice after treatment with HDAC inhibitor, SAHA. A, QRT-PCR of human IL-13Ro2 in implanted pancreatic tumors after SAHA and IL-13-PE treatment. Tumors were harvested next day after IL-13-PE treatment and total RNA extracted. Data shown is ratio of human IL-13R $\alpha 2 / \beta$-actin expression and multiplied by 1000 for convenience. Bars, SD of triplicate determinations. B, qRT-PCR of mouse IL-13Ro2 in mice organs after SAHA and IL-13-PE treatment. Tissues were harvested at the same time point as in panel A and total RNA extracted. Data shown is ratio of mouse $/ L-13 R \alpha 2 / \beta$-actin expression and multiplied by 100 for convenience. C, IHC of human IL-13R $\alpha 2$ in implanted pancreatic tumors after SAHA and IL-13-PE treatment. D, IHC of mouse IL-13R $\alpha 2$ in mice organs after SAHA and IL-13-PE treatment. Liver, brain, kidney, pancreas, lung and spleen were fixed for immunostaining of mouse IL-13R 2 as visualized by Alexa555. Nucleus was counterstained by DAPI.

positive pancreatic cancer cell lines, but not in IL13R $\alpha 2$-negative cell lines. In contrast, histones in IL13R $\alpha 2$-negative pancreatic cell lines and normal cell lines were highly methylated, but not in IL-13R 22 positive cell lines. The reason for the differential histone acetylation and methylation is not known but appears to correlate with IL-13R $\alpha 2$ expression and may be responsible for variability of IL-13R $\alpha 2$ expression in cancer cells.

The role of histone acetylation was explored further using histone deacetylase (HDAC) inhibitors. Interestingly, in the presence of HDAC inhibitors (TSA and NaB), IL$13 R \alpha 2$ expression was significantly induced in IL-13R $\alpha 2-$ negative cell lines whose histones were not acetylated compared to IL-13R $\alpha 2$-positive cell lines in which histones were acetylated. The mechanism of differential IL-13R $\alpha 2$ regulation was examined. IL-13 signals through IL-13R $\alpha 2$ via the AP-1 pathway and inactivation of this pathway by JNK and AP-1 inhibition suppressed IL-13R 2 expression in IL-13R $\alpha 2$-positive cell lines. Additionally, inactivation of the AP-1 pathway also suppressed induction of IL$13 R \alpha 2$ by HDAC inhibitors in IL-13R $\alpha 2$-negative cell 
lines. In accordance, $\mathrm{Wu}$ et al. have reported the importance of c-jun, which is a member of AP-1 transcription factor, in IL-13R $\alpha 2$ expression [32]. These observations indicate a strong correlation between transcription factor and histone acetylation in the IL-13R $\alpha 2$ at the promoter region.

The significance of IL-13R $\alpha 2$ upregulation by HDAC inhibitors was examined. As expected, IL-13 induced STAT6 phosphorylation in IL-13R $\alpha 2$-negative pancreatic cancer cell lines (Supplementary Figure 5). Interestingly, TSA increased IL-13R $\alpha 2$ expression, but suppressed STAT6 phosphorylation induced by IL-13 treatment. The suppression of STAT6 phosphorylation by TSA was inhibited by IL-13R $\alpha 2$ RNAi indicating that IL-13R $\alpha 2$ is directly involved in this counter-regulation (data not shown). Similarly, as expected, IL-13 did not induce MMPs expression in IL-13R $\alpha 2$-negative pancreatic cancer cell lines [28]. However, when cells were treated with TSA, IL-13 could increase MMP-9, 12 and 14 mRNA as IL-13R $\alpha 2$ expression was upregulated. In contrast, MMPs were not induced by TSA when IL-13R $\alpha 2$ was knocked-down by RNAi or IL-13 signaling was inhibited by JNK inhibitor.

We took advantage of upregulation of IL-13R $\alpha 2$ in pancreatic cancer cell lines and hypothesized that HDAC inhibitors may enhance the sensitivity of IL-13 receptortargeted immunotoxin, IL-13-PE, in pancreatic cancers. We have previously demonstrated that IL-13-PE is a powerful anti-cancer agent, causing regression of IL13R $\alpha 2$-positive human tumors derived from variety of human cancers including pancreatic cancer $[15,16]$. However, for efficacy, these tumors must express high levels of IL-13R $\alpha 2$. Since cancer is a heterogeneous disease, druginduced upregulation of IL-13R $\alpha 2$ could be used in cancers expressing even low levels of IL-13 $\alpha 2$ to enhance the intensity of the immunotoxin anti-cancer response. Indeed, we demonstrate that pre-treatment of tumor cell lines in vitro with TSA enhanced their sensitivity to IL-13PE and made IL-13R $\alpha 2$-negative cell lines extremely sensitive to IL-13-PE. In contrast, TSA treatment did not sensitize normal epithelial cell lines, thus providing a therapeutic advantage of targeting tumors but not normal tissues. Consequently, the use of HDAC inhibitors may open a new avenue of treating pancreatic cancer when combined with IL-13-PE. It is possible that HDAC inhibitors may also sensitize tumors to other immunotoxins targeting different antigens or cell surface receptors.

The reason why normal epithelial cells are not sensitized to IL-13-PE by TSA is not clear. Epithelial cells exhibit a similar histone modification pattern to IL13R $\alpha 2$-negative pancreatic cancer cell lines but, IL$13 R \alpha 2$ is not upregulated in normal epithelial cells by HDAC inhibitors. This may be because normal cell lines show no c-jun activity, while IL-13R $\alpha 2$-negative pancreatic cancer cell lines show a 2-6 fold increase in c-jun activity indicating that TSA induction of high levels of IL-13R $\alpha 2$ is dependent on the AP-1/c-jun pathway.

We also demonstrate that HDAC inhibitors when combined with IL-13-PE cause more dramatic tumor responses than those caused by either agent alone in two pancreatic cancer models. Pancreatic cancers in situ were not sensitive to IL-13-PE as they do not naturally express IL-13R $\alpha 2$ and TSA or SAHA alone showed only modest to moderate anti-tumor effects. However, when TSA or SAHA were combined with IL13-PE a dramatic inhibition of tumor growth was observed. In agreement with our observations, HDAC inhibition has been reported in combination therapies for other types of cancer. Combination therapy of SAHA and retinoic acid has been examined for resistant acute promyelocytic leukemia in which SAHA enhanced the anti-cancer effect of retinoic acid [33]. Another HDAC inhibitor, LAQ824, is reported to be effective in combination with adoptive T-cell transfer therapy against mouse model of melanoma [34]. These authors hypothesized that LAQ824 increases the tumor-associated antigen expression enhancing the antitumor effectiveness of $\mathrm{T}$ cell therapy.

It is important to note that while HDAC inhibition enhanced the remarkable anti-cancer effects of IL-13-PE in pancreatic cancer models in vivo by upregulating IL$13 R \alpha 2$ in the tumors, no significant upregulation of IL$13 R \alpha 2$ expression was observed in any vital organs. In addition, no detectable histological changes were observed in any vital organs. Although IL-13-PE was injected locally, our findings confirm that this novel combination therapeutic approach is safe. Future studies will examine systemic administration of IL-13-PE in combination with HDAC inhibitors in syngenic animal tumor models. Taken together, our results provide support for testing this novel combination in the clinic for the therapy of human cancer including pancreatic cancer for which no therapeutic options are currently available.

\section{Additional material}

Additional file 1: Figure S1: DNA methylation status of upstream sequences from IL-13R $\alpha 2$ promoter site. DNA methylation status was examined by bisulfite-sequencing at the $\mathrm{CpG}$ site located about 100 bases upstream from IL-13R $\alpha 2$ promoter region. Methylated and unmethylated alleles are shown as solid and open circles, respectively.

Additional file 2: Figure S2: AP-1 transcription factor activity in pancreatic cancer cell lines. C-jun (A) and c-Fos (B) activity in pancreatic cancer and normal cell lines. Protein samples were extracted from nuclear fraction. AP-1 activity was measured by ELISA.

Additional file 3: Figure S3: Histological finding of vital organs in SAHA and IL-13-PE treated mice. Tissue specimens were obtained from mice liver, kidney, spleen, pancreas, brain and lung in each group of SAHA and IL-13-PE treated experiment (day 19) for hematoxylin and eosin staining. 
Additional file 4: Figure S4: IL-13R $\alpha 2$ expression is upregulated in pancreatic tumors after treatment with TSA. QRT-PCR of human IL13Ro2 in implanted human pancreatic tumors, Panc-1 (A) and ASPC-1 (B) after TSA and IL-13-PE treatment. Tumors were harvested next day after IL-13-PE treatment ended and total RNA was extracted. Data shown is ratio of human $/ L-13 R \alpha 2 / \beta$-actin expression. Bars, SD of triplicate determinations.

Additional file 5: Figure S5: HDAC inhibitor inhibits IL-13 induced STAT6 activation through induction of IL-13R $\alpha 2$. Western blotting of phospho- and total STAT6 after incubation of cells with TSA and/or SP600125. Cells were incubated with $1 \mu \mathrm{M}$ TSA and/or $10 \mu \mathrm{M}$ SP600125 for 24 hours. Fifteen minutes before harvest, IL-13 was added to the culture medium. Protein samples were prepared from nuclear compartment and separated by electrophoresis.

\section{Abbreviations}

IL-13Ra2: interleukin 13 receptor alpha 2; IL-13-PE: interleukin 13 pseudomonas exotoxin.

\section{Acknowledgements}

We thank Drs. Brenton McCright and John Thomas for reviewing the manuscript and Dr. Takashi Furusawa from National Cancer Institute, protein section and members of Tumor Vaccines and Biotechnology Branch, Division of Cellular and Gene Therapies, Center for Biologics Evaluation and Research and for their suggestions.

\section{Authors' contributions}

Conceived and designed the experiments: TF, BHJ, RKP. Performed the experiments: TF. Analyzed the data: TF. Wrote the paper: TF, BHJ, RKP. All authors have read and approved the final manuscript.

\section{Competing interests}

The authors declare that they have no competing interests.

Received: 15 March 2011 Accepted: 8 April 2011 Published: 8 April 2011

\section{References}

1. Kawakami K, Terabe M, Kawakami M, Berzofsky JA, Puri RK: Characterization of a novel human tumor antigen interleukin-13 receptor alpha2 chain. Cancer Res 2006, 66:4434-4442.

2. Scanlan MJ, Gure AO, Jungbluth AA, Old LJ, Chen YT: Cancer/testis antigens: an expanding family of targets for cancer immunotherapy. Immunol Rev 2002, 188:22-32.

3. Husain SR, Joshi BH, Puri RK: Interleukin-13 receptor as a unique target for anti-glioblastoma therapy. Int J Cancer 2001, 92:168-175.

4. Puri RK, Leland P, Obiri NI, Husain SR, Kreitman RJ, Haas GP, Pastan I, Debinski W: Targeting of interleukin-13 receptor on human renal cell carcinoma cells by a recombinant chimeric protein composed of interleukin-13 and a truncated form of Pseudomonas exotoxin A (PE38QQR). Blood 1996, 87:4333-4339.

5. Kawakami K, Husain SR, Kawakami M, Puri RK: Improved anti-tumor activity and safety of interleukin-13 receptor targeted cytotoxin by systemic continuous administration in head and neck cancer xenograft model. Mol Med 2002, 8:487-494.

6. Husain SR, Obiri NI, Gill P, Zheng T, Pastan I, Debinski W, Puri RK: Receptor for interleukin 13 on AIDS-associated Kaposi's sarcoma cells serves as a new target for a potent Pseudomonas exotoxin-based chimeric toxin protein. Clin Cancer Res 1997, 3:151-156.

7. Kioi M, Kawakami M, Shimamura T, Husain SR, Puri RK: Interleukin-13 receptor alpha2 chain: a potential biomarker and molecular target for ovarian cancer therapy. Cancer 2006, 107:1407-1418.

8. Debinski W, Obiri NI, Powers SK, Pastan I, Puri RK: Human glioma cells overexpress receptors for interleukin 13 and are extremely sensitive to a novel chimeric protein composed of interleukin 13 and pseudomonas exotoxin. Clin Cancer Res 1995, 1:1253-1258.

9. Debinski W, Obiri NI, Pastan I, Puri RK: A novel chimeric protein composed of interleukin 13 and Pseudomonas exotoxin is highly cytotoxic to human carcinoma cells expressing receptors for interleukin 13 and interleukin 4. J Biol Chem 1995, 270:16775-16780.

10. Joshi BH, Kawakami K, Leland P, Puri RK: Heterogeneity in interleukin-13 receptor expression and subunit structure in squamous cell carcinoma of head and neck: differential sensitivity to chimeric fusion proteins comprised of interleukin-13 and a mutated form of Pseudomonas exotoxin. Clin Cancer Res 2002, 8:1948-1956.

11. Joshi BH, Puri RK: Optimization of expression and purification of two biologically active chimeric fusion proteins that consist of human interleukin-13 and Pseudomonas exotoxin in Escherichia coli. Protein Expr Purif 2005, 39:189-198.

12. Kawakami K, Kawakami M, Kioi M, Husain SR, Puri RK: Distribution kinetics of targeted cytotoxin in glioma by bolus or convection-enhanced delivery in a murine model. J Neurosurg 2004, 101:1004-1011.

13. Joshi BH, Hogaboam C, Dover P, Husain SR, Puri RK: Role of interleukin-13 in cancer, pulmonary fibrosis, and other $\mathrm{T}(\mathrm{H}) 2$-type diseases. Vitam Horm 2006, 74:479-504.

14. Kunwar S, Prados MD, Chang SM, Berger MS, Lang FF, Piepmeier JM, Sampson JH, Ram Z, Gutin PH, Gibbons RD, et al: Direct intracerebral delivery of cintredekin besudotox (IL13-PE38QQR) in recurrent malignant glioma: a report by the Cintredekin Besudotox Intraparenchymal Study Group. J Clin Oncol 2007, 25:837-844.

15. Shimamura T, Fujisawa T, Husain SR, Joshi B, Puri RK: Interleukin 13 mediates signal transduction through interleukin 13 receptor alpha2 in pancreatic ductal adenocarcinoma: role of IL-13 Pseudomonas exotoxin in pancreatic cancer therapy. Clin Cancer Res 2009, 16:577-586.

16. Fujisawa T, Nakashima H, Nakajima A, Joshi BH, Puri RK: Targeting IL13Ralpha2 in human pancreatic ductal adenocarcinoma with combination therapy of IL-13-PE and gemcitabine. Int J Cancer 2010.

17. Allen C, Paraskevakou G, lankov I, Giannini C, Schroeder M, Sarkaria J, Puri RK, Russell SJ, Galanis E: Interleukin-13 displaying retargeted oncolytic measles virus strains have significant activity against gliomas with improved specificity. Mol Ther 2008, 16:1556-1564.

18. Kahlon KS, Brown C, Cooper LJ, Raubitschek A, Forman SJ, Jensen MC: Specific recognition and killing of glioblastoma multiforme by interleukin 13-zetakine redirected cytolytic T cells. Cancer Res 2004, 64:9160-9166.

19. Egger G, Liang G, Aparicio A, Jones PA: Epigenetics in human disease and prospects for epigenetic therapy. Nature 2004, 429:457-463.

20. Urdinguio RG, Sanchez-Mut JV, Esteller M: Epigenetic mechanisms in neurological diseases: genes, syndromes, and therapies. Lancet Neurol 2009, 8:1056-1072.

21. Lennartsson A, Ekwall K: Histone modification patterns and epigenetic codes. Biochim Biophys Acta 2009, 1790:863-868.

22. Bird A: Perceptions of epigenetics. Nature 2007, 447:396-398.

23. Eberharter A, Becker PB: Histone acetylation: a switch between repressive and permissive chromatin. Second in review series on chromatin dynamics. EMBO Rep 2002, 3:224-229.

24. Kelly WK, Marks PA: Drug insight: Histone deacetylase inhibitorsdevelopment of the new targeted anticancer agent suberoylanilide hydroxamic acid. Nat Clin Pract Oncol 2005, 2:150-157.

25. Marks $P A$, Jiang $X$ : Histone deacetylase inhibitors in programmed cell death and cancer therapy. Cell Cycle 2005, 4:549-551.

26. Duvic M, Talpur R, Ni X, Zhang C, Hazarika P, Kelly C, Chiao JH, Reilly JF, Ricker JL, Richon VM, Frankel SR: Phase 2 trial of oral vorinostat (suberoylanilide hydroxamic acid, SAHA) for refractory cutaneous T-cell lymphoma (CTCL). Blood 2007, 109:31-39.

27. Joshi BH, Husain SR, Puri RK: Preclinical studies with IL-13PE38QQR for therapy of malignant glioma. Drug News Perspect 2000, 13:599-605.

28. Fujisawa T, Joshi B, Nakajima A, Puri RK: A novel role of interleukin-13 receptor alpha2 in pancreatic cancer invasion and metastasis. Cancer Res 2009, 69:8678-8685.

29. Joshi BH, Leland P, Calvo A, Green JE, Puri RK: Human adrenomedullin upregulates interleukin-13 receptor alpha2 chain in prostate cancer in vitro and in vivo: a novel approach to sensitize prostate cancer to anticancer therapy. Cancer Res 2008, 68:9311-9317.

30. Joshi BH, Plautz GE, Puri RK: Interleukin-13 receptor alpha chain: a novel tumor-associated transmembrane protein in primary explants of human malignant gliomas. Cancer Res 2000, 60:1168-1172.

31. Kawakami K, Kawakami M, Husain SR, Puri RK: Potent antitumor activity of IL-13 cytotoxin in human pancreatic tumors engineered to express IL-13 receptor alpha2 chain in vivo. Gene Ther 2003, 10:1116-1128. 
32. Wu AH, Low WC: Molecular cloning and identification of the human interleukin 13 alpha 2 receptor (IL-13Ra2) promoter. Neuro Oncol 2003, 5:179-187.

33. He LZ, Tolentino T, Grayson P, Zhong S, Warrell RP Jr, Rifkind RA, Marks PA, Richon VM, Pandolfi PP: Histone deacetylase inhibitors induce remission in transgenic models of therapy-resistant acute promyelocytic leukemia. J Clin Invest 2001, 108:1321-1330.

34. Vo DD, Prins RM, Begley JL, Donahue TR, Morris LF, Bruhn KW, de la Rocha P, Yang MY, Mok S, Garban HJ, et al: Enhanced antitumor activity induced by adoptive T-cell transfer and adjunctive use of the histone deacetylase inhibitor LAQ824. Cancer Res 2009, 69:8693-8699.

doi:10.1186/1479-5876-9-37

Cite this article as: Fujisawa et al:: Histone modification enhances the effectiveness of IL-13 receptor targeted immunotoxin in murine models of human pancreatic cancer. Journal of Translational Medicine 2011 9:37.

\section{Submit your next manuscript to BioMed Central} and take full advantage of:

- Convenient online submission

- Thorough peer review

- No space constraints or color figure charges

- Immediate publication on acceptance

- Inclusion in PubMed, CAS, Scopus and Google Scholar

- Research which is freely available for redistribution

Submit your manuscript at www.biomedcentral.com/submit 